\title{
Preparation and Evaluation of Paracetamol Effervescent Tablets under Normal and Exaggerated Storage Conditions
}

\author{
Rehana Sultana, Krishna Sarker and Sakina Sultana \\ Department of Pharmacy, Jahangirnagar University, Dhaka-1342, Bangladesh
}

\begin{abstract}
A single blind study was conducted to prepare and evaluate paracetamol effervescent tablets. Potency, content uniformity, diameter, thickness and crushing strength of the prepared tablets were used as the bench mark parameters for quality assessment. Our results showed that all parameters met official values except for friability. The performance of the tablets in terms of duration of effervescence was investigated under high stresses of humidity as well as at low and high temperatures. The duration of the investigational period lasted for 3 days and results showed an increase in effervescence time in each case. In this study, the normal effervescence time at $111.00 \pm 14.22$ seconds was changed to $286.13 \pm 55.18$ seconds, $140.38 \pm 21.59$ seconds and $158.63 \pm 26.14$ seconds under high humidity, at refrigeration (representing cool temperature) and at high temperature, respectively. Here, a long term performance study was also conducted under normal storage conditions spanning a period of 60 days. Duration of effervescence on day 1 was $212.54 \pm 0.34$ seconds, but at the end of 60 days the duration increased to $634.23 \pm 0.65$ seconds. In the present study the changes in organoleptic properties were also evaluated. Results showed that the properties remained the same over a period of 60 days while the potency of the drug reduced from $99 \%$ to $95 \%$.
\end{abstract}

Key words: Effervescent tablet, paracetamol, evaluation, high humidity, low- and high-temperature.

\section{Introduction}

Tablet is the most common and popular solid dosage form of drugs. About $90 \%$ of the total prescriptions contain various tablet dosage forms including effervescent tablet (e-tab). The uniqueness of e-tabs is that they set up a rapid onset of action due to fast disintegration followed by fast dissolution (Lachmann et al., 1990; Jacob et al., 2009). E-tabs in presence of water make drug solutions more palatable than any other solid dosage forms due to the releases of carbon dioxide in the form of effervescence. Paracetamol (PCT) is a universally accepted analgesic and antipyretic drug since early 1940s. The chemical name of this drug is acetaminophen and it belongs to the non-salicylate analgesic group. This drug has well-established metabolic and pharmacokinetic (pK) profiles. In home and abroad, PCT is readily available in various dosage forms including solution, suspension, suppository and tablet with an exception of effervescent tablet forms. Researchers are always trying to develop new formulations as part of innovative technology and thus formulation of e-tabs has become a prime area of research interest. As continuation of such researches, efforts were taken to formulate paracetamol effervescent tablets (PCT e-tab) (Yanze et al., 2000; Rygnestad et al., 2000; Ameen et al., 2006; Nagandra et al., 2009). But ironically approaches to formulate e-tabs are very limited in our country and as such PCT e-tab is not available in the local market. Therefore, this study was designed to formulate PCT e-tab suitable for our country and to evaluate their physico-chemical properties. including performance testing (in terms of effervescence) under various exaggerated storage conditions over a time period of 3 days as well as long term performance study over a period of 60 days under normal storage conditions.

\section{Materials and Method}

Materials: Paracetamol, sodium bicarbonate, sodium carbonate, citric acid, PVP (K 30), methyl paraben, propyl paraben, sodium saccharin, sodium benzoate and absolute alcohol were purchased from local market.

Correspondence to: Professor Dr. Sakina Sultana, E-mail: sultana_s2003@yahoo.co.uk 
Method: In this study, e-tabs were prepared by using a customized formula following an officially recommended method with the exception that the binder paste was made in absolute alcohol. For the study two sets of tablets (each set comprising of 30 tablets) were prepared. After preparation, the e-tabs were doubly wrapped in thick layered poly bags and were kept in an air tight container under normal storage conditions until testing commenced.

Physical property evaluation: E-tablets were checked for content uniformity, diameter, thickness, crushing strength and friability according to the published procedures (Carter, 1986; Lachman et al., 1986). Here, content uniformity of tablets was determined by using an electronic balance. Tablet diameter and thickness were measured by using a slide caliper, while Monsanto hardness tester, calibrated in $\mathrm{kg} / \mathrm{cm}^{2}$, was used for measuring the crushing strength of the tablets.

Chemical property evaluation: Potency gives a quantitative measurement of drug present in the tablets. The potency of the tablets was determined by using a UV/Vis spectrophotometer (Shimadzu-1600, Japan) at $\lambda_{\max } 257 \mathrm{~nm}$.

Accelerated testing of performance criteria: In order to perform the tests, e-tabs were subjected to an artificially created exaggerated storage conditions of high stress like high humidity, low temperature and high temperature. For inducing high humidity desiccators were filled partly with plain water and then doubly wrapped PCT e-tabs $(\mathrm{n}=8)$ were kept on the upper compartment. After three days tablets were taken out and performance study was conducted using plain water $(200 \mathrm{ml})$ at room temperature. Time was noted from the initiation of effervescence until completion with the help of a stopwatch capable of recording $1 / 100^{\text {th }}$ fraction of a second. The time difference representing the duration of effervescence was considered as a marker of performance of e-tabs. Other tests involving high stress were done in the same manner, except for inducing low temperature a refrigerator and for inducing high temperature a 100 watts bulb fitted to a close cabinet were used. For comparison, one set of e-tabs packed in the same way was kept under normal storage conditions for an equal period of time. In the same way the long term performance test spanning a period of 60 days was also conducted on doubly wrapped e-tabs kept in an air tight container under normal storage conditions.
Evaluation of organoleptic properties: Here, the test size, shape, surface smoothness, taste $\&$ palatability, and mouth feeling of PCT e-tabs were evaluated. Six human volunteers of age ranging between 18-22 years (irrespective of gender) checked the properties on day 1 , day 30 and day 60 . The volunteers gave emphasis on tablet deformation (if any) caused by chipping, picking and surface grittiness. They made visual and manual inspection. To check taste and mouth feeling they drank water based e-tablet solutions. Comments on the properties were expressed according to the typical thermometer scale used for consumer products (Lachman et al., 1986).

\section{Results and Discussion}

The observed physico-chemical properties of PCT etabs on day-1 are shown in Table 1 . Tablet potency was found to be $>98 \%$ and average net weight of tablets was found as $0.790 \mathrm{mg}(\mathrm{n}=8)$. Both the parameters were found within the official limit of acceptance (Carter 1987; Lachman et al., 1986; BP 1993). In the study regarding uniformity of size and shape, tablet diameter and thickness were measured. Average diameter was found as $12.41 \mathrm{~mm}$ and the deviation was within the official value as well. However, the average crushing strength of tablets was found as $1.63 \mathrm{~kg} \pm 0.49(\mathrm{n}=8)$ and value could not be compared with an official value because the parameter for effervescent tablets varies many folds. The friability of the prepared tablets was found as 3\% and the respective official value is <1\% (Lachman et al., 1986). Thus, our etabs appeared to be friable three times higher than normal tablets. This difference might be due to procedural error or could be due to formulation error. Since an established method was followed, the procedural error could not a reason for such variation. Other reasons that were involved could be the errors in formulation. In the study, PVP paste was made with absolute alcohol. It is well known that PVP is a good binder and it imparts cohesiveness to a powder mixture prior to tablet preparation. Such cohesiveness is important for maintaining the tensile strength of tablets (APhA, 1986; Lachman et al., 1986). Therefore, it may be possible that the PVP paste used for the tablet preparation was not adequate enough to impart cohesiveness needed to resist material release from tablet surface upon collision that 
was done in the friabilator. As a result friability was found to be high. However, this fact needs further exploration before confirmation. Table 2 shows the changes in effervescence time for the PCT e-tabs kept under exaggerated storage conditions for a period of 3 days. Our results showed that on day 1 the duration of effervescence was $111 \pm 14.22$ seconds $(n=10)$. In humidified conditions the duration of effervescence significantly increased and the value became $286.13 \pm 55.18$ seconds ( $n$ $=10$ ). Such results were expected. In humid condition a slow reaction occurred and caused effervescence to take

Table 1. Physico-chemical properties of tablets on day 1.

\begin{tabular}{lcccccc}
\hline Values & Potency & $\begin{array}{c}\text { Net content } \\
(\text { weight } \\
(\mathrm{mg})\end{array}$ & $\begin{array}{c}\text { Tablet } \\
\text { diameter } \\
(\mathrm{mm})\end{array}$ & $\begin{array}{c}\text { Thickness of } \\
\text { tablets }(\mathrm{mm})\end{array}$ & $\begin{array}{c}\text { Crshing } \\
\text { strength } \\
(\mathrm{kg})\end{array}$ & $\begin{array}{c}\text { Friability } \\
(\%)\end{array}$ \\
\hline $\begin{array}{l}\text { Experimental } \\
(\mathrm{n}=8)\end{array}$ & 98.59 & $0.79 \pm 12.01$ & $12.41 \pm 0.37$ & $4.91 \pm 0.12$ & $1.63 \pm 0.49$ & 3 \\
$\begin{array}{l}\text { Official limit of acceptance } \\
\text { in percentile }\end{array}$ & $94.91^{\oplus}$ & & \pm 15 & \pm 5 & \pm 5 & 4 \\
\hline
\end{tabular}

Values are given in mean $\pm \mathrm{SD} ;{ }^{\oplus}$ value obtained on day 60 .

Table 2. Accelerated stability tests results of PCT e-tabs under high stresses for 3 days.

\begin{tabular}{lcc}
\hline Storage conditions & $\begin{array}{c}\text { Duration of effervescence on day 1 } \\
\text { (seconds) }\end{array}$ & $\begin{array}{c}\text { Duration of effervescence on day } 3 \\
\text { (seconds) }\end{array}$ \\
\hline Normal condition & $111 \pm 14.22(\mathrm{n}=10)$ & $115 \pm 10.21(\mathrm{n}=10)$ \\
High temperature (100 watts) & $111 \pm 14.22(\mathrm{n}=10)$ & $158.63 \pm 26.14(\mathrm{n}=10)$ \\
Humidified & $111 \pm 14.22(\mathrm{n}=10)$ & $286.13 \pm 55.18(\mathrm{n}=10)$ \\
Refrigeration & $111 \pm 14.22(\mathrm{n}=10)$ & $140.38 \pm 21.59(\mathrm{n}=10)$ \\
\hline
\end{tabular}

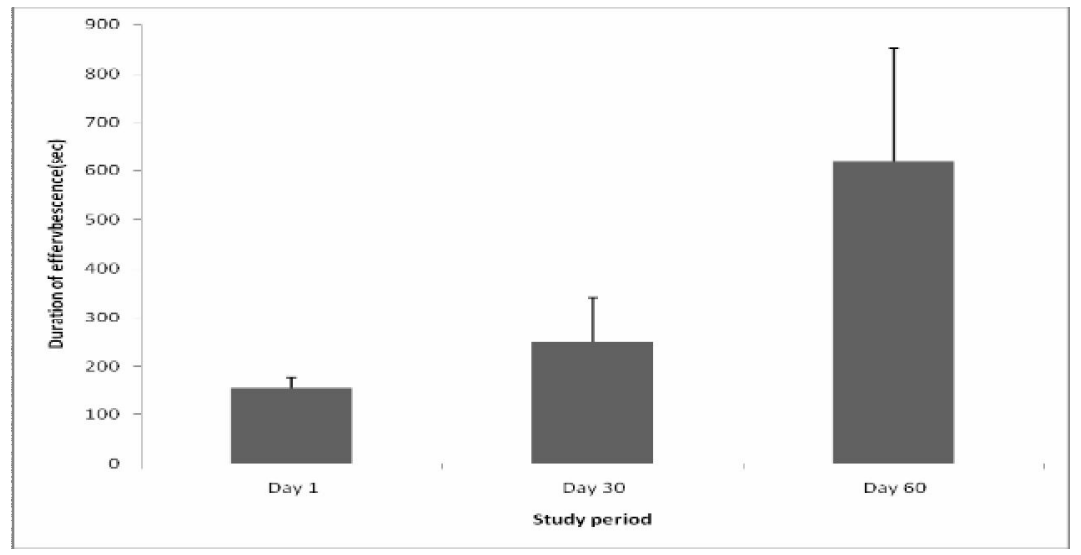

Figure 1. Duration of effervescence of PCT e-tablets over a period of 60 days.

Table 3. Changes in organoleptic properties in PCT e-tabs within 60 days.

\begin{tabular}{lccc}
\hline Organoleptic properties & Day 1 & Day 30 & Day 60 \\
\hline Chipping & Negligible & Negligible & Negligible \\
Picking + Sticking & Not seen & Not seen & Not seen \\
Any crack & Not seen & Not seen & Not seen \\
Gritty particles & Not seen & Not seen & Not seen \\
Surface shine & Good & Good & Good \\
Mouth feel & Good & Good & Good \\
Palatability & Good & Good & Good \\
\hline
\end{tabular}


place in a slow manner and prolonged the duration of effervescence. In the study storage under refrigeration was another exaggerated storage condition to produce high stress. So effervescent PCT e-tabs were kept in a refrigerator and after 3 days effervescence test was done. Results showed a significant change in effervescent time period. Here the normal effervescence period of $111 \pm$ 14.22 seconds increased to $140.38 \pm 21.59$ seconds $(n=10)$ ( $<<0.05$, Mann -Whitney U test, one sided). Such result was unexpected because refrigeration always offers dehumidified condition and keeps things dry. If it did happen there would not be an increase in time period of effervescence. So e-tabs were not in a dehumidified condition. It could be that there had been a local condensation of entrapped air that was present in the poly bags used for wrapping e-tabs. Therefore there might have some chemical reactions causing a significant change in the period of effervescence before and after refrigeration. However, this also needs further study for confirmation. In the present study a long term performance test was carried out over a period of 60 days with an interval of 30 days. Results are shown in Figure 1 and from the figure an increasing trend of effervescence is evident. Our results showed almost 2 folds and 4 folds increased duration of effervescence at the end of 30 days and 60 days, respectively than that of on day 1 . Such results might not be unusual because in the study the doubly wrapped tablets were kept in an air tight container. It is possible that under such arrangement the storage condition was not strong enough to restrict air permeation into the container and hence into the tablets. There might have been a slow entrance of air and hence moisture into e-tabs and causing a chemical reaction to proceed. As a result, the effervescence process was slowed down as time passed on. Organoleptic properties of PCT e-tabs were checked (Table 3) on two occasions- one at the beginning and another at the end of the study. Human volunteers checked the properties and found no changes over 60 days (table $\mathrm{T}$ ) including a slight change in potency (Table 1).

\section{Conclusions}

From the above study, it can be concluded that a successful formulation of PCT e-tabs is possible and it would be a remarkable addition to our pharmaceutical field.

\section{References}

Ameen, V.Z, Pobiner, B.F., Giquere, G.C and Carter, E.G. 2006. Ranitidine ((Zantac) syrup versus ranitidine effervescent tablets (Zantac) in children a single centre taste performance studies. Paediatrics Drugs. 8, 265-270.

American Pharmaceutical Association. 1986. Handbook of Excipients. Washington DC. USA.

British Pharmacopoeia. 1993. $\mathrm{XV}^{\text {th }}$ edition, British Pharmacopoeia Commission Secretariat, UK.

Carter, S.J. 1987. Copper and Gunn's Dispensing for Pharmaceutical Student. $12^{\text {th }}$ edition, CBS Publishers and Distributors, India.

Hannan, J.M.A. 2007. Medical \& Pharmaceutical Statistics. $1^{\text {st }}$ edition, Sangbed publishers, Dhaka, Bangladesh.

Jacob, S., Shirwarker, A., and Nair, A. 2009. Preparation and evaluation of fast disintegrating effervescent tablets of glibenclamide. Drug Dev. Ind. Pharam. 35, 321-328.

Lachman, L., Lieberman, H.A. and Kanig, J.K. 1986. The Theory and Practice of Industrial Pharmacy. $4^{\text {th }}$ edition, Lea and Febiger, Philadelphia, USA.

Lievermann, H.A., Lachman, L. and Schwartz, J.B. 1990. Pharmaceutical Dosage Forms. Marcel Dekker Inc., New York.

Nagandra, K.D., Raju, S.A., Sirsand, S.B., Para, S.B., Para, M.S. and Rampure, M.V. 2009. Fast dissolving tablets of fexofenadine $\mathrm{HCl}$ by effervescent method. Indian J. Pharm. Sci. 71, 116-119.

Rygnestad, T., Zahlsen, K. and Samdal, F.A. 2000. Absorption of effervescent paracetamol tablets relative to ordinary paracetamol tablets in healthy volunteers. Eur. J. Clin. Pharmacol. 56, 141-143.

Yanze, F. M., Duruc, C. and Jacob, M. 2000. A process to produce effervescent tablets by fluidized bed dryer melt granulation. Drug Dev. Ind. Pharam. 26, 1167-1176. 